agency in Ltverpool recetved $\$ 300000$ (Hunt, 1995).

We have no doubt that this money was thoroughly deserved and will be spent wisely on improving and delivering services to those with drug problems. However, we are concerned that such large grants may cause an imbalance in the provision of services when not part of an overall local strategy. The position of agencies which do not recetve such sums may be undermined by not having these resources avallable to them.

Most areas will expect agencies to adhere to any strategy negotlated locally (Liverpool Health Authority, 1995), but funds that bypass the normal funding mechanisms can undermine this strategy. Applications for funding would normally have to submit bids to health purchasers (or joint commissioning consortia if social services are involved) and these would have to satisfy criteria on effectiveness, outcomes and quality.

Self-interest groups with no need to comply with these regulations can proselytise their service, justifying their own agenda to win funds, whereas statutory services will be committed to the public health agenda. Lottery Commissions may be unaware of the wider implications and are unwittingly encouraging perverse incentives. They will never be allowed to fund mainstream statutory health services, possibly to the detriment of professional care and to those who are committed to the public health agenda.

The new Drug Action Teams (1995) will have to be aware that any decisions they make on the way services should be formed or purchased may be contrary to the initiatives supported by the Lottery Commission. Other health disciplines should be aware they may face similar problems.

Drug Action Tenus (1995) Tackling Drugs Together: A Strategy for England 1995. CM 2846. London: HMSO.

HUN, A. (1995) Charity numbers come up. Ltwerpool Bcho, 20 November, 15.

LVERPOOL HEALTH AUTHORTY (1995) Strategy: Substance Misuse. Ltverpool: Annual Public Health Report.

Cuve L. MORRISON

The Maryland Centre, 8 Maryland Street, Lwerpool L1 9DE

\section{Certificate of Completion of Specialist Training (CCST): implications for higher training in pojchiatry}

Sir: There are a number of concerns regarding the implementation of the recommendations of the Calman Report which are germane to psychiatry. The Royal College of Psychiatrists proposes to award CCSTs after a total of three years of higher professional training, with a minimum of two years in a chosen spectality. Our understanding is that individuals training in specialities (old age, forensic, etc) will only be granted a CCST in that speciality. For a trainee to be awarded a CCST in both general adult psychiatry and a speciality will require a minimum of four years' training (two years in general adult psychiatry and two years in a speciality). Dual accreditation is highly desirable. The approach to provision of psychiatric services by Trusts is liable to change, and cliniclans in specialities may be required to undertake work in general adult psychiatry in the future. Furthermore, participation in 'on call' rotas which cover general adult psychiatry may also require accreditation as a general psychiatrist. The consequence of this is that the length of training for disciplines other than general adult psychiatry has been increased, contrary to one of the principles underpinning the Calman Report. This is ironic given the dearth of suitably qualified applicants in some psychiatric specialities, for example old age psychiatry. In addition, any doctors training in the UK wishing to practise elsewhere in the EU may not be able to do so without CCST in general psychiatry as many EU counties may not recognise accreditation in some specialities.

The situation in the rest of Europe is very different. The Calman exercise took place in order to bring the length of specialist training in the UK into line with the rest of Europe. Despite this, considerable inequality remains. According to the College (Colleglate Trainees' Committee, 1995), the award of a CCST, whether granted in the UK or other countries in the European economic area will bring automatic inclusion in the new Specialist List. In many EU countries individuals will obtain CCST or its equivalent after just four years' postgraduate training. Under these circumstances they will be included in the Specialist List held by the General Medical Council (GMC) and hence be eligible for consultant posts in the UK.

Courgate Trannes' Comartrex (1995) Colleglate Trainees' Committce position on structural training. Psychiatric Bulletin. 19, 455-458.

Jorge J. Cerviula Maudsley Hospital, London

JAMES P. WARNER

Royal Free Hospital School of Medictne, University of London, Rowland Hill Street, London NW3 2PF

Sir: Unfortunately Drs Cervilla and Warner have not portrayed the College's proposals concerning the award of the CCST in the psychiatric specialities accurately.

In each of the recognised specialities (child and adolescent psychiatry, forensic psychiatry, general psychiatry, the psychiatry of learning disability, psychiatry of old age and psychotherapy). 